REVISTA NOMADÍAS

Julio 2011, Número No 13, 147-151

\title{
Las mujeres y las luchas árabes por la liberación.
}

\author{
Kamal Cumsille M. \\ Universidad de Chile \\ kcumsille@gmail.com
}

¿Por qué una retórica de defensa de la democracia y al mismo tiempo un silencio político y un irrestricto respaldo económico y militar a dictaduras sangrientas? Es la pregunta que la actual Intifada ha planteado a EEUU y a las potencias europeas, así como ha dejado al descubierto su escandaloso doble estándar. A las feministas occidentales se les podría plantear una interrogante similar: ¿por qué una retórica de emancipación anti-velo y al mismo tiempo velar a mujeres no veladas? Y pues, se trata de que, sea por la llamada "amenaza islamista" (en el caso del respaldo a las dictaduras árabes por parte de las potencias) o por el velo del orientalismo y la pretensión de universalidad de los discursos occidentales sobre libertad y liberación (entran aquí hombres y mujeres), la mujer árabe se ha visto invisibilizada tanto por el sistema patriarcal del que es víctima (al igual que todas las mujeres del planeta), por las fuerzas conservadoras de sus sociedades y también, por el mismo orientalismo que coloniza las mentes de las feministas occidentales. De manera que, Edward Said tenía absolutamente la razón cuando en su célebre Orientalismo, decía que Occidente ha "orientalizado" a Oriente porque le convenía que así sea.

En un excelente libro de reciente aparición Yo maté a Sherezade. Confesiones de una mujer árabe furiosa (del que el dossier que comento da noticia), la poeta y periodista libanesa Joumana Haddad da cuenta de este problema en las primeras páginas, donde en su "Nota al lector" nos relata el hecho a partir del cual le surgió la idea de escribir dicho libro. Se trata de una entrevista en la que una periodista se le mostraba perpleja ante su figura, para ella muy excepcional, de una mujer árabe "emancipada" que escribe poesía erótica y edita una revista sobre el cuerpo, a lo que Haddad respondió, según ella misma reconoce "de un modo bastante grosero" diciendo: "No me considero tan excep- 
cional. Hay muchas «mujeres árabes liberadas» como yo. Y si, como usted dice, no sabe de nuestra existencia, entonces ese es su problema, no el nuestro" ${ }^{1}$. El lugar en que este prejuicio pone a la mujer árabe que lucha por la emancipación es el de eterna seguidora de la feminista occidental, ya emancipada y que lleva la avanzada en la lucha por los derechos de su género, pues se trata del problema del léxico de lo universal, sobre el que occidente reclama toda propiedad, esto también corre para hombres y mujeres. Ahora, tampoco se trata de tergiversar la realidad ni de ser tan condescendientes con el mundo árabe: la situación de la mujer en la mayoría de estos países es desastrosa tanto en aspectos legales como familiares, sin embargo, la historia de sus luchas nos muestra que hace ya bastante tiempo la mujer árabe dejó de ser esa víctima "velada" que nos exhibe el orientalismo con tanta insistencia, y del que también se hacen eco las feministas occidentales, sea por mero desconocimiento, o bien por la convicción de que el sujeto femenino es obra de su "civilización".

Pues ¿por qué tanta consternación frente a la masiva participación de las mujeres en las revueltas? Como si se tratara de la primera vez que las mujeres árabes salen a la calle para manifestarse públicamente por derechos políticos y sociales. También esto corre para el juego espectacular de las imágenes, pues, si no es por Al Jazeera, nos quedamos con la imagen que (tal como muestran las fotos del dossier que estamos comentando) las mujeres árabes son un conjunto de anónimas veladas.

Esto no es así desde ningún punto de vista. La aparición pública de la mujer árabe no comenzó el año 2011, si quiera en mayor medida que en períodos anteriores; y tampoco son un conjunto de anónimas veladas. La mujer árabe ha jugado un rol importante,- no menor que el de los hombres, y tampoco menor que el de sus congéneres de otras culturas- en todos los procesos políticos y culturales de la historia de su región, y si ese rol se ha visto invisibilizado, es porque como dije antes, no lo han provocado solamente las fuerzas conservadoras de sus países, sino también el orientalismo que impregna el discurso del occidente que dice defender sus libertades. Todavía hay que agregar, el rol de liderazgo tampoco es menor que el de las mujeres de otras culturas, pues occidente y sus periferias colonizadas que reclaman esta identidad, tampoco puede jactarse de tener gran cantidad de líderes femeninas (no me refiero a líderes feministas por cierto, sino a líderes para toda la sociedad). De manera que, es necesario aclarar: las mujeres árabes han jugado un importante rol en lo que fue la Nahda (renacimiento cultural árabe 
de entre la segunda mitad del siglo XIX y primeras décadas del $\mathrm{XX}$ ), en la lucha anticolonial, en los movimientos revolucionarios de resistencia contra Israel, así como en las revueltas actuales, de las cuales participan, no como mujeres, sino como parte de un pueblo entero que reclama libertades políticas de las que no gozan hombres ni mujeres. Tal vez, un estudio más profundo sobre el tema deba quedar pendiente para un futuro trabajo, donde no se trate el rol particular de las mujeres en estos procesos, sino de igual a igual con sus pares varones, cosa que tampoco se observa en las historias políticas "generales" del mundo árabe. Así, quienes debemos quitarnos el velo somos nosotros mismos, y de este modo, permitirnos sacar del anonimato en que nos aparecen, a todas esas mujeres cuyo papel ha sido crucial en los procesos del mundo árabe. En lo que sigue, sólo pretendo dar noticia de algunas de ellas que dan testimonio de esa realidad.

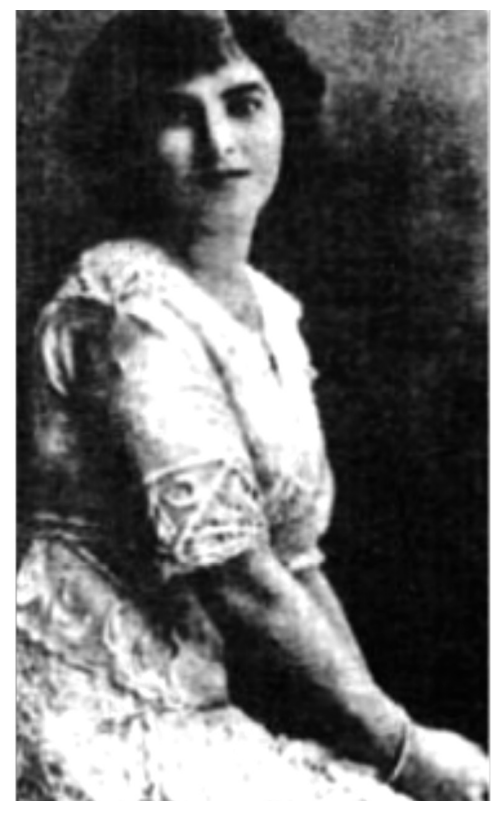

May Ziadeh (1886-1941): Una figura central del renacimiento árabe. Nació en Nazaret, Palestina. Entre los años 1912-1916, formó en El Cairo el "Salón literario", instancia en la que reuniría semanalmente en tertulias a las más grandes figuras del renacimiento cultural árabe de la época, entre ellos: los egipcios Taha Husayn, Ahmed Lutfi Al-Sayed, Mahmud Abbas Al-Aqqad, Ya'qub Sarruf, Ahmed Shawqi; y los libaneses Khalil Mutran, Antoine Gemayel, entre otros. Estudio filosofía, historia y lenguas. Además del árabe y el francés, que fue el idioma de sus primeros dos libros de poesía, manejaba cinco idiomas, entre ellos el español. Publicó más de quince libros, entre poemarios, colecciones de artículos de crítica literaria, traducciones y escritos políticos. Lamentablemente, más que por su trabajo, es conocida por su amor epistolar con el poeta Gibran Khalil Gibran (con quien nunca se conocieron personalmente ya que éste vivía en Nueva York), y al que ella hizo famoso en los países árabes a través de artículos sobre la obra del poeta en los principales periódicos de Egipto y Líbano. 


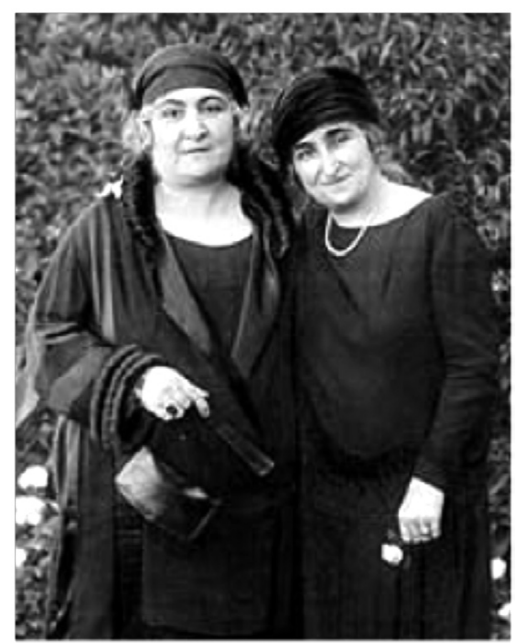

Hoda Shaarawi (izquierda) y Safia Zaghloul (derecha). Dos mujeres egipcias que en 1919, participaron de la revolución nacional en contra de la ocupación británica jugando un papel protagónico. En 1923, Hoda Shaarawi con Saiza Nabarawi fundaron la Federación de Mujeres, asociación que además de estar inscrita activamente en el movimiento anticolonial, luchó por la educación y los derechos de las mujeres. Uno de sus logros fue el que en 1924, la edad mínima para contraer matrimonio en el caso de las niñas se elevara a los 16 años. En 1921, Amelia Sakakini y Zalikha Al-Sharabi habían fundado una federación similar en Palestina.

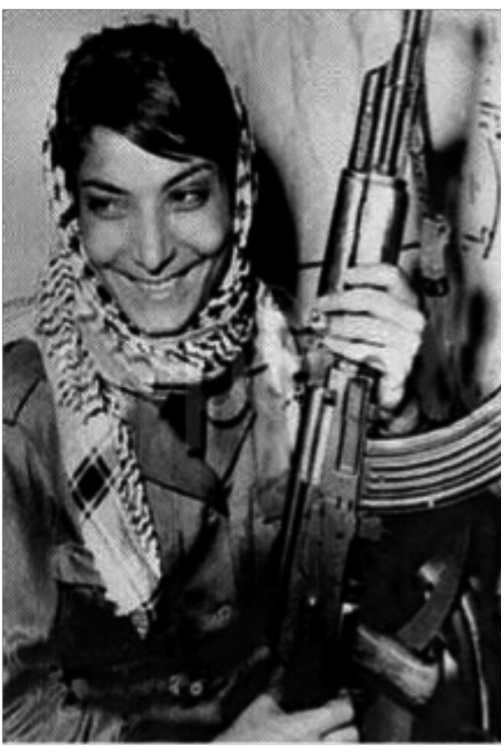

Leyla Khaled (1944- ): Nació en Haifa, cuando Palestina aún estaba bajo mandato británico. En 1948 su familia se ve forzada a salir al Líbano, como parte de los más de 800 mil refugiados palestinos que debieron dejar sus hogares tras la instalación de Israel. A los 15 años se unió al Movimiento Nacionalista Árabe, cuya facción palestina en Líbano dirigía George Habash, y que tras la guerra de 1967 se convertiría en el Frente Popular para la Liberación de Palestina -FPLP. Durante algunos años ejerció como profesora en Kuwait. En los años 1969 y 1970 participó de dos secuestros de aviones, lo que la convirtió en la primera mujer en integrar comandos de operaciones de envergadura en la resistencia palestina. Actualmente vive en Jordania, es miembro del Consejo Nacional Palestino y participa regularmente del Foro Social Mundial. En 2005, la cineasta palestino-sueca Lina Makboul realizó un film sobre su vida titulado: "Leila Khaled hijacker". 


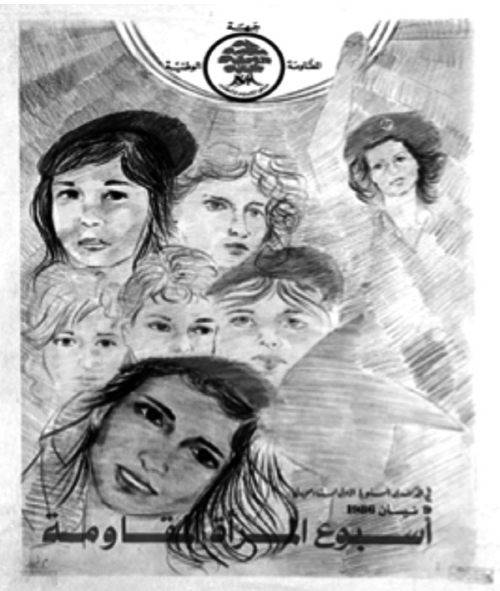

Mujeres de la resistencia contra la ocupación israelí en el sur del Líbano

En 1982, en el marco de la Guerra Civil libanesa, y con el respaldo de la Falange, Israel invade el país. Tras el asedio al que somete a su capital, Beirut, entre junio y septiembre de ese año (el que termina con la masacre de los campamentos palestinos de Sabra y Shatila), Israel mantendrá invadida una porción de territorio en el sur, invasión que duró hasta mayo de 2000. Además del conocido "Partido de Dios" (Hezbollah), uno de los más importantes movimientos que resistieron a esta invasión fue el llamado "Frente de Resistencia Patriótica Libanesa", integrado por diversos partidos y facciones laicas libanesas y palestinas. En este frente, las mujeres jugaron un importante papel. Entre ellas destaca Sana' Mihaidli, proveniente de las filas del Partido Nacionalista Sirio, que en 1985 participó de una operación suicida en contra de un convoy militar israelí, tras lo cual ha sido recordada como "La novia del Sur". La imagen que se muestra es un poster del frente aludido, en conmemoración de la "Semana de la mujer de la resistencia", que homenajea a nueve mujeres mártires.

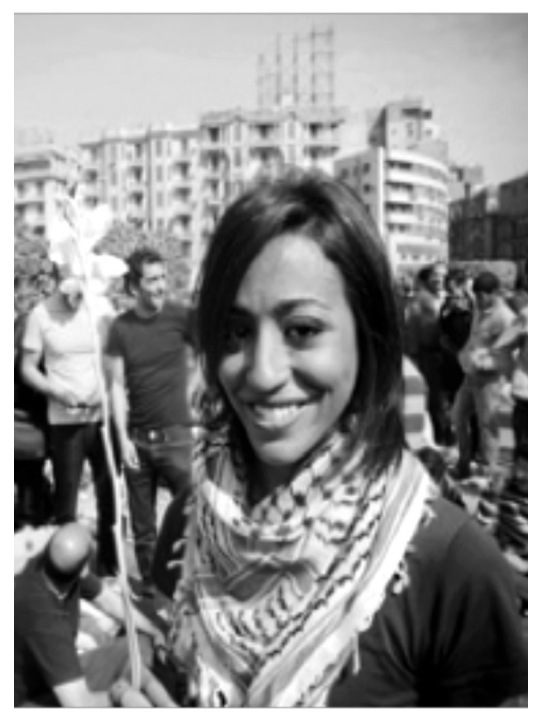

Gigi Ibrahim, de 24 años, cuenta entre las mujeres protagonistas de la revuelta egipcia que terminó con el régimen de Hosni Mubarak en febrero del presente año. Estudió Ciencia Política en la Universidad Americana de El Cairo, donde comenzó su actividad política. Como dirigente estudiantil tomó contacto con el movimiento obrero, contribuyendo a la articulación política de los diversos grupos que expresaban demandas sociales. Al igual que decenas de miles de personas, acampó 
durante 18 días en la Plaza Tahrir hasta producir la dimisión del presidente. En su página de Facebook, se pueden leer sus notas críticas sobre la situación política de Egipto, así como sus comunicados que instaban a la comunidad universitaria a unirse a las huelgas de los trabajadores y trabajadoras en 2010.

\section{Notas}

1 Haddad, Joumana. Yo maté a Sherezade. Confesiones de una mujer árabe furiosa. Buenos Aires: Debate, 2011, p.13.

\section{Bibliografía}

Al-Saadawi, Nawal. La cara desnuda de la mujer árabe. Madrid: Editorial Horas y Horas, 1991.

Haddad, Joumana. Yo maté a Sherezade. Confesiones de una mujer árabe furiosa. Buenos Aires: Debate, 2011.

Khrais, Bilal. "Lebanon's women warriors", En: Al Jazeera English, 24 de abril de 2010. http: / / english.aljazeera.net

Naib, Fatma. "Women of the revolution", En: Al Jazeera English, 19 de febrero de 2011. http: / / english.aljazeera.net

Wolf, Naomi. "The Middle East feminist revolution", En: Al Jazeera English, 04 de marzo de 2011. http:/ / english.aljazeera.net

Centro de Documentación Digital, Universidad Americana de Beirut. http:/ / ddc.aub.edu.lb/ 